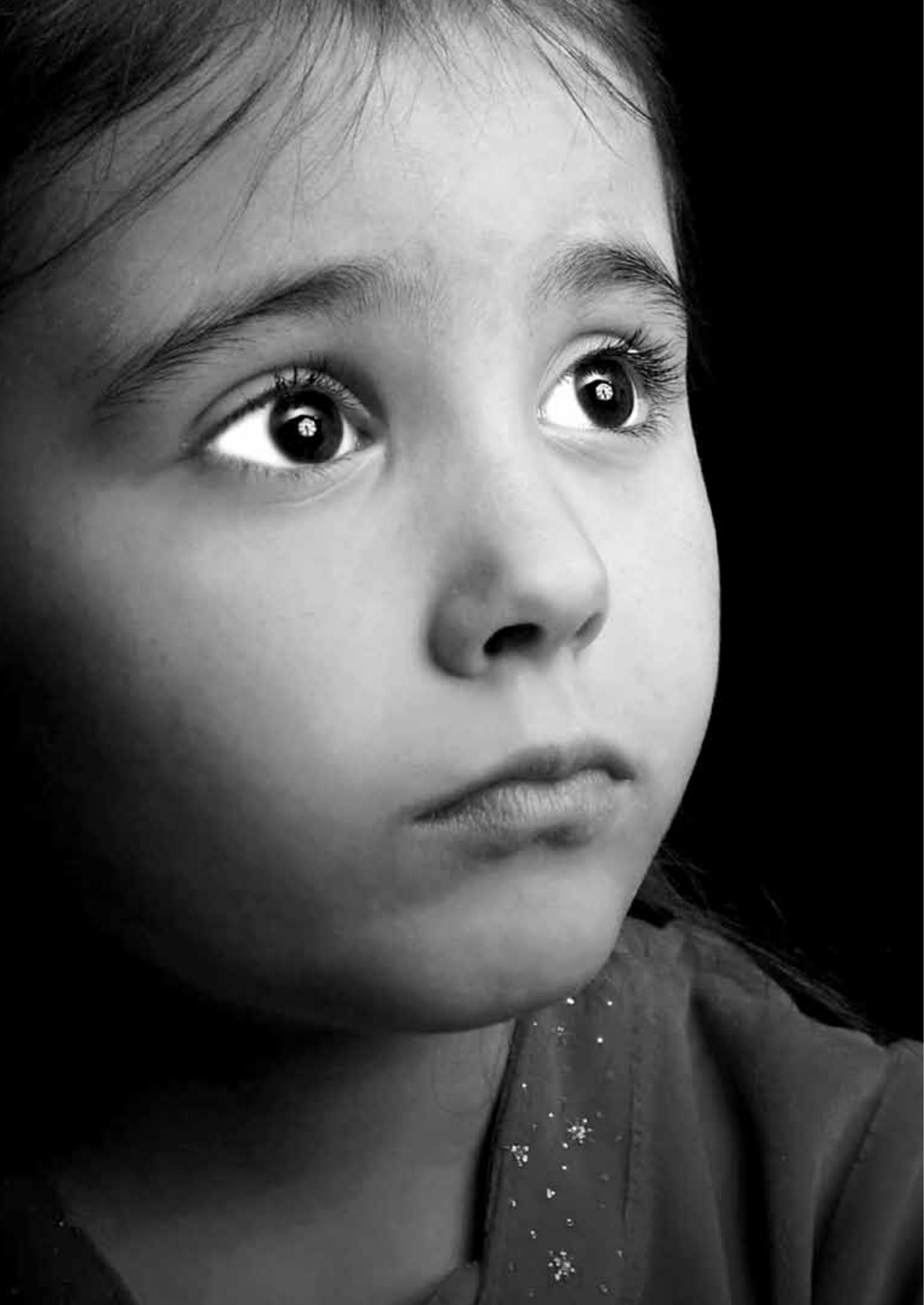




\section{Improving Mental Heal
Outcomes for Children \\ and Youth Exposed to \\ Abuse and Neglect}

Ene Underwood

Without doubt, children and youth

exposed to abuse and neglect rank among

our most vulnerable citizens when it comes

to mental health. 


\begin{abstract}
Children exposed to abuse and neglect are at significantly higher risk of developing mental health conditions than are children who grow up in stable families. Multiple complexities arise in supporting the needs of these vulnerable children: complex family circumstances; the need to balance the goals of protecting the children and strengthening family connections; and the involvement of multiple players from biological families to foster parents to case workers to children's mental health professionals. This article draws on case studies, the literature and proven initiatives that have been implemented in a number of children's aid societies in Ontario to demonstrate four strategies that can improve mental health outcomes for children exposed to abuse and neglect. These strategies are increasing admission prevention and early intervention to support at-risk youth at home; supporting transitions from intensive residential treatment back to the community; ensuring youth transitioning to the adult system have the supports they need; and increasing integration in service delivery between children's mental health and child welfare.
\end{abstract}

"Kayley" is a third-generation client of one of Ontario's Children's Aid Societies (CASs). Fetal alcohol exposed and diagnosed with multiple mental health conditions, Kayley began life with her birth mother who was frequently absent and unable to provide for her young daughter. When she was three, Kayley was adopted by her grandmother. Kayley first came to the attention of CAS at the age of five because her grandmother was struggling with her own depression and because CAS was concerned that she was being abusive in her attempts to discipline Kayley. Today, Kayley is 16 years old. Her complex mental health needs have resulted in multiple placements in treatment facilities and treatment foster homes - often resulting in extended periods of time away from her home community. In spite of her many moves, CAS has assisted in enabling her to maintain contact with her grandmother and her siblings. Although she is currently doing well following a recent discharge from intensive residential treatment, she remains a high-risk youth and lacks many of the skills she will need to successfully transition to adulthood.

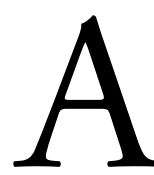

s Kayley's story demonstrates, there are multiple layers of complexity in supporting the mental health needs of children and youth who are involved with child welfare. There are often complex family circumstances, and in many cases there are parents with mental health conditions, addictions or other challenges that require support. There is the need to balance the protection of the child with the goal of retaining and strengthening family connections. There are multiple players beyond the family and the mental health team: foster parents, the children's worker, the resource worker supporting the foster parents and, in some cases, adoption workers or other staff from the child welfare team. Finally, regarding youth involved in child welfare who are not reunited with their birth families or placed for adoption, there are the added challenges of preparing these youth for a successful transition to adulthood and to the adult mental health system.

This article examines the inter-relationship between childhood maltreatment and children's mental health and proposes four strategies for supporting this vulnerable group of children and youth.

\section{Link between Child Maltreatment and Mental Health}

Over the past decade, there has been a growing appreciation of the significant relationships between child maltreatment and lifelong health. Evidence has demonstrated links between childhood maltreatment and a range of illnesses in adulthood, such as fibromyalgia, irritable bowel syndrome, chronic lung disease and cancer (Fuller-Thomson and Brennenstuhl 2009; Gilbert 2009; Krug et al. 2002). Perhaps the most prevalent of these health linkages - in both childhood and adulthood - is the relationship of child abuse and neglect to mental health conditions.

While the prevalence of mental health conditions in the overall child population is reported at $14 \%$ (Waddell et al. 2002), the rate in children involved in child welfare are much higher. In a study of Ontario crown wards, Burge (2007) found that $32 \%$ had at least one diagnosed mental disorder. In a similar study, Ford et al. (2007) reported that $46 \%$ of children in care had at least one mental health condition, three times the rate $(15 \%)$ found among children from disadvantaged homes. Another study found children in foster care to be 16 times more likely to have psychiatric diagnoses and eight times more likely to be taking psychotropic medication than were children in community samples (Racusin et al. 2005). A 2009 report from British Columbia stated that youth in care were 17 times more likely to be hospitalized for mental health issues than were the general public (Representative for Children and Youth of British Columbia 2009).

Higher-than-average mental health needs are not observed just in children in foster care. Though less studied than children removed from their homes, children receiving child welfare services while remaining in their homes have also been found to have higher documented needs for mental health services than children not involved in child welfare (Burns et al. 2004; Farmer et al. 2001).

The mental health impacts of child abuse and neglect can take many forms: depression, anxiety disorders, eating disorders, sexual disorders, suicidal behaviour and substance abuse (Draper 
et al. 2008). In addition, victims may have low self esteem, psychological distress and difficulties establishing intimate relationships (Draper et al 2008). The 2008 Canadian Incidence Study of Reported Child Abuse and Neglect (Public Health Agency of Canada 2010) found that in cases of substantiated maltreatment, $19 \%$ of children and youth exhibited symptoms of depression, anxiety, or withdrawal; $15 \%$ showed aggression; $14 \%$ exhibited attachment issues; and 11\% demonstrated symptoms of attention deficit hyperactivity disorder (ADHD).

Beyond the profound impact that this combination of childhood maltreatment and poor mental health can have on individuals, it also exacts a tremendous economic toll on society. Poor health, low educational attainment, lower workforce participation, higher rates of homelessness, teenage pregnancies, crime and incarceration have all been correlated with childhood maltreatment. One Australian study has estimated the lifetime costs associated with outcomes for young people leaving care at $\$ 740,000$ per individual (Raman et al. 2005). No doubt this figure is even higher for young people leaving care who have serious mental health conditions.

\section{What Is Behind the Relationship between Childhood Maltreatment and Children's Mental Health?}

Four overall factors have been linked to the relationship between childhood maltreatment and children's mental health: early neurological development; direct impacts of the abuse itself; biological and environmental factors associated with parental mental health; and, finally, factors arising from the disruption and trauma associated with being involved in the child welfare system (Burge 2007).

Early attachment theorists refer to the "inner working model" that children develop at an early age based on a mental representation of their parent. This mental image allows children to be comforted at times when their actual parent is not physically present. Researchers have found that children who are maltreated develop dysfunctional inner working models. The result is poor affect regulation, perceptual bias, self-defeating thoughts and defective interpersonal behaviour. In short, the internal working model in children who have experienced neglect and abuse can become a framework for serious maladaptive behaviour (Crittenden 2000; Sanders and Fulton 2009, June).

Farmer et al. (2001) demonstrated relationships between parental risk factors and the use of mental health services by children and youth involved with child welfare. Highest parental risk factors associated with children's mental health use were found to be: physical impairment (49.7\%), cognitive impairment (47.3\%), severe mental illness (34.0\%), impaired parenting skills $(30.4 \%)$, monetary problems $(30.2 \%)$, drug and alcohol abuse (28.3\%) and domestic violence $(25.5 \%)$. The 2008 Canadian Incidence Study (Public Health Agency

\section{Child Welfare and Children's Mental} Health in Ontario

In 2009-2010, spending on child welfare in Ontario represented approximately $\$ 1.4$ billion. In many ways, the organization of child welfare in Ontario mirrors the organization of healthcare. Child welfare is delivered through 53 independently governed agencies who receive funding through transfer payments from the provincial government. In parallel to healthcare, where the largest proportion of spending is represented by the relatively small portion of patients who receive in-patient care, the largest proportion of spending in child welfare relates to services to children who are "in care" - foster care or group care. In Ontario child welfare, approximately 27,000 children and youth receive in-care services each year, accounting for approximately $40 \%$ of total expenditures. A much larger number of children and youth who have been maltreated or are at risk for maltreatment are supported in their homes with their families. The Ontario Association of Children's Aid Societies estimates that for every one child in care, another nine children are being supported by CASs at home with their families.

The 2009-2010 spending on core children's mental health services in Ontario was \$384 million (excluding funding for complex special needs). Transfer-payment recipients include stand-alone agencies that provide child and youth mental health services, 17 hospital-based outpatient programs and First Nation and non-profit Aboriginal organizations and service agencies, including 27 friendship centres. The provincial government also funds the Provincial Centre of Excellence for Child and Youth Mental Health at the Children's Hospital of Eastern Ontario, and the Ontario Child and Youth Telepsychiatry Program. Beyond the formal mental health system, many children and youth receive mental health services through schools, private providers, CASs and other sources. As with child welfare services, the vast majority of children's mental health services are communitybased, and children requiring intensive out-of-home treatment are the minority.

of Canada 2010) found that in cases of substantiated child maltreatment, $27 \%$ of primary caregivers had mental health issues and $38 \%$ had alcohol or drug addictions.

Children and youth who require out-of-home care as a result of maltreatment are exposed to additional risks - particularly as a result of multiple moves and, in rare cases, as a result of abuse by other children or caregivers while in out-of-home care. 
A study of children in foster care in England found that the rate of mental disorders tended to decrease with the length of time in their current placement. The rate fell from $49 \%$ on children and youth in their current placement for less than a year to $31 \%$ in children and youth in their placement for greater than five years (Meltzer et al. 2003).

\section{Four Strategies to Make a Difference}

Without doubt, children and youth exposed to abuse and neglect rank among our most vulnerable citizens when it comes to mental health. The inherent complexities of their needs together with the confounding variable of multiple systems responding to these needs require a heightened level of collaboration and integration. Four strategies have been proven to make a difference in the mental health outcomes for this vulnerable population:

1. Increase admission prevention and early intervention to support at-risk youth at home.

2. Support transitions from intensive residential treatment back to the community.

3. Ensure that youth transitioning to the adult system have the supports they need.

4. Increase integration in service delivery between children's mental health and child welfare.

\section{Increase Admission Prevention and Early Intervention to Support At-Risk Youth at Home}

By the age of five, "Darius" had been exposed to domestic violence at home and abuse by his mother. He began to exhibit increasingly aggressive and explosive behaviours in preschool, and by age six was expelled from grade one. His father and stepmother very much wanted to keep Darius at home, but they were showing signs of extreme distress and didn't know how to cope with his aggression toward his younger siblings and his challenging behaviours. A CAS worker arranged an assessment of Darius's mental health needs and then collaborated with the local children's mental health organization and board of education to put a plan in place. Arrangements were made for a child and youth worker to spend half-days with Darius to give his father some relief and to transport him to a special school support program three days a week for one-on-one teaching. In parallel, his father and stepmother participated in a parenting skills program and received one-on-one parent coaching from their CAS worker. Today, Darius is nine years old, living at home and doing well in a specialized school program for children with mental health needs.
Leaders and clinicians in healthcare are very familiar with the term "iatrogenic" disease. This refers to the risks that can arise as a result of the treatment itself or from the experience of being hospitalized - leading to adverse events. In child welfare, the decision to protect a child by removing him from his home presents its own risks. O'Donnell et al. (2008) point to emerging research that demonstrates that children placed in foster care can sometimes be more damaged by the trauma of being removed from their parents (and, in some cases, being subject to multiple placements) than if had they remained with their families.

The challenge, however, is that vulnerable children who remain with their families are often less likely to receive the mental health services that they need than if they were in foster care. In one study of children with child welfare involvement with comparable mental health needs, children in foster care were roughly three times as likely to be receiving mental health services as were children at home with their families (Leslie et al. 2005). Comparable trends have been demonstrated with children who are in kinship care - living with relatives as an alternative to foster care. While youth in kinship care experience more placement stability and higher levels of well-being than youth in foster care, these youth are less likely access mental health services (Leslie et al. 2005; Winokur et al. 2009). Similarly, studies have found that children and youth with younger caregivers are less likely to use mental health services and, if they do access them, are more likely to drop out of treatment (Villigrana 2010).

\section{The challenge, however, is that vulnerable children who remain with their families are often less likely to receive the mental health services that they need than if they were in foster care.}

Yet, there is evidence that timely access to mental health services can reduce the risk of out-of-home placement for at-risk children and youth. A 2006 Tennessee study of children and youth served by an integrated child welfare and youth justice agency reported that $65 \%$ of children and youth had significant mental health, behavioural or psychosocial challenges. The study found that access to specialty mental health services reduced the probability of an out-of-home placement by $36 \%$ during the 18-month study period (Glisson and Green 2006).

The question becomes this: with so much evidence favouring early intervention, how do we increase the odds of at-risk kids getting the benefit of these services while keeping them safe at home? It's not easy. In Ontario, policy changes in 2006 associated with the Transformation Agenda for child welfare placed increase emphasis on admission prevention and early intervention. These policy changes envisioned a future in which CASs 
would work proactively with vulnerable families and community resources to support children at home. Sometimes this would mean directly supporting the needs of children, and sometimes it would mean addressing parent risk factors in terms of their own mental health, addictions or parenting capacity. However, the current funding formula for the child welfare sector has remained somewhat misaligned with this policy direction. Moreover, wait times for children's mental health services are frequently out of step with needs. The same is true of access to community supports to address parental risk factors.

Identification of needs is also a challenge. A 2009 survey of Ontario CASs found that only 55\% endorsed using some form of structured screening tool in the identification of mental health needs of children and youth in their care - and there was significant variation in the tools being used (Czincz and Romano 2009).

Notwithstanding the challenges, several Ontario CASs have initiated proactive programs in partnership with local mental health providers to provide timely in-home support to at-risk children and their families. As an example, the Family and Children's Services of St. Thomas and Elgin (a CAS) employs a children's mental health worker who provides mental health counselling and support for children and families with the goal of preventing admissions and supporting the reunification of foster children back home with their families. The initiative has proven very successful in providing effective mental health support in a community where the wait time for a local mental health provider is typically one year.

\section{Support Transitions from Intensive Residential Treatment Back to the Community}

"Arjun" was 13 when he was transferred from a CAS foster home to a mental health treatment facility as a result of escalating aggression, substance abuse and conflict with his peers. As a young boy, Arjun had been sexually abused by his father, who had subsequently been incarcerated. Arjun's mother disappeared when he was three. After 18 months at the treatment centre, Arjun had made met all his treatment goals and discharge to foster care was recommended. The CAS felt that, given Arjun's history, it would be unable to find a suitable foster-care home. Two months later with no identified family-based option in view, the treatment centre recommended that the CAS find a group care placement that would foster independence and a more home-like setting for Arjun. Six months after he was ready for discharge, a placement had still not been found. Arjun became discouraged and began to regress. Ultimately, Arjun's behaviours escalated to the point where he was charged with assault and placed in a youth justice facility.
As Arjun's story illustrates, timely and appropriate discharge can be crucial to overall treatment outcomes. For youth with serious attachment disorders, the risks of discharge delays can be great as the secure environment of residential treatment centres can provoke a false sense of safety and security that exacerbates the feelings of abandonment when the prospect of discharge is imminent (personal communication, C. MacLeod, executive director, Roberts-Smart Centre, 2010).

Stewart et al. (2010) have reported on a two-year study of CAS-involved and non-CAS-involved youth with comparable mental health needs at time of admission. The study found that six months after the start of treatment, CAS-involved youth showed a greater improvement than did non-CAS-involved youth. However, two years post-discharge, the non-CAS youth continued to show improvements. For CAS-involved youth, the pattern was different. While the CAS-involved youth still showed marked improvements versus their status at time of admission, they had lost ground from where they were six months into treatment.

The authors posited several explanations for this decline among CAS-involved youth. Caseworker involvement during treatment is sometimes variable for CAS-involved youth. Sometimes a youth's caseworker may change during treatment. Family involvement may also be variable during and following treatment. In some cases, a youth may be returning to a different home setting than the one left prior to admission.

Informal interviews with leaders from child welfare and children's mental health providers have also confirmed the imperative for increasing the level of continuity for CAS-involved youth during and after their residential treatment. Programs have been cited in which staff from the treatment centre provide intensive pre-discharge training and post-discharge support to foster parents, child welfare workers, schools and even the local police to encourage the successful transition of at-risk youth back into the community. Some communities benefit from having a mechanism to provide a "central clearinghouse" that child welfare and other agencies can access for information and case resolution for very-high-risk youth.

\section{Ensure That Youth Transitioning to the Adult System Have the Supports They Need}

"Carly" was admitted to care when she was 15, when conflict at home became extreme. She has been diagnosed with ADHD, obsessive compulsive disorder, mood disorder, anxiety disorder and paranoid personality traits. She refuses all medications but one. After a brief and successful period in a residential treatment facility, Carly transitioned to a foster home where she remains today at the age of 18. Although her CAS has worked hard to introduce Carly to services in the adult mental health sector, she has refused to partici- 
pate, citing that they are too stringent and structured. Her older brother had also been in care and has complex mental health needs. He is now 23, but Carly, the CAS and the adult mental health agency to which he was referred cannot find him. Carly last saw him two years ago. She has since shared with her CAS worker that she is sure he is homeless or in jail.

By some estimates, as much as half of all lifetime mental health disorders begin in the middle teenage years, and three quarters by the mid-20s (Kessler et al. 2007). Hence, it is critical for us as a society to ensure that we are effectively responding to and supporting the needs of young adults as they make the critical passage from youth to adulthood.

For youth who have experienced childhood abuse or neglect - and most particularly, for youth in foster care who will "age out of the system" without the support of a permanent family - navigating the passage from adolescence to adulthood can be precarious. In a study of 106 young people leaving care, Dixon (2008) found that $12 \%$ reported mental health problems at the outset and that this figure doubled by the 12- to 15 -month follow-up. There is considerable evidence that these youth are not accessing the mental health services they need in their early adult years. In a study of 616 young adults who had contact with the child welfare system, Ringeisen et al. (2009) found a significant decrease in the use of mental health services from $48 \%$ in mid-adolescence to $14 \%$ five to six years later.

Multiple factors contribute to this mismatch between the mental health needs and service access of young adults with former child welfare involvement: the movement from a childoriented to an adult-oriented system; a lack of insurance for medication and counselling; an aversion to anything that represents "the system"; and other factors. Individuals' age at time of leaving care is also a significant factor, with early leavers having a lower likelihood of accessing supports and consequent poorer outcomes (Dixon et al. 2006).

So ... how do we fix this? In Ontario, the Select Committee on Mental Health and Addictions (2010) has recommended the reintegration of child and youth mental health services into the healthcare system. This structural change might strengthen connections between adolescent and adult mental health services. However, this direction has been criticized as having the potential to weaken linkages between children's mental health and all other children's services, including child welfare. Moreover, there are concerns that that this direction could overly focus on the pathology of mental illness rather than a more holistic determinants-of-health approach to child and youth mental health.

Some CASs and children's mental health providers have experienced success in formalizing proactive collaborative planning with the adult mental health sector. In the Erie St. Clair Local Health Integration Network, the child welfare and children's mental health agencies have collaborated with the community adult mental health agencies to develop a protocol for supporting these important youth transitions. This protocol sets out a process through which all CAS-involved youth who may require adult mental health services are identified prior to their 16th birthday. A timely and supportive transition process is then designed for each youth, and each youth is fully engaged in informing and participating in this process.

Many advocates have been urging for a number of changes that would improve the odds for older youth in care as they navigate the mental health and other challenges associated with their transition to adulthood. A major theme relates to changing the rules to enable youth in care to remain with their foster families beyond their 18th birthday - the current date at which youth age out of care in Ontario. Advocates such as the National Youth in Care Network (www.youthincare.ca) and others (Laidlaw Foundation 2010; Ontario Association of Children's Aid Societies 2006; Rowden 2010, May 21) propose that young adults should be able to remain in their foster homes until the age of 21 and then be supported up to the age of 25 by way of emotional, education and living supports and access to health benefits programs. There is also increasing emphasis on encouraging adoption or legal guardianship for older youth. All of these strategies would go a long way to improving the continuity of services and social supports for older youth in care and improving their mental health outcomes during and after this critical transition to adulthood.

\section{Increase Integration in Service Delivery between Children's Mental Health and Child Welfare}

"Robert" lives in one of the communities in Ontario where child welfare and children's mental health are delivered through a single integrated organization. At age 12, Robert was brought into care after a teacher expressed concerns about his escalating violent behaviours, anxiety and limited apparent parental supervision. Robert was placed in a small intensive treatment residence operated by the integrated agency. Case conferences engaged Robert's workers from the child welfare and the children's mental health teams as well as his family in determining the best course of treatment for him. His workers knew that moves were extremely traumatic for Robert. As a result, the team worked together to plan an extended transition period from the residential treatment home. Foster parents were identified for Robert months before his discharge, and they worked with the team and Robert to plan for his transition. Once in his foster home, both Robert and his foster parents benefited from ongoing supports from the combined child welfare and children's mental health team. Today, Robert is 18, living in the same foster home and supported by the same workers in planning for his transition to adulthood. 
The theme of enhancing coordination and timely access to children's mental health services recurs in every new policy paper and every conversation with leaders in the child welfare and children's mental health sector. There is an understandable concern that too great an integration between child welfare and children's mental health could result in disproportionate access for child welfare-involved youth at the expense of youth in the general population with comparable needs. However, this pattern is not borne out in the research. Hurlburt (2004) found that increasing the coordination between child welfare and children's mental health services resulted in a greater likelihood of service access correlating with need, regardless of child welfare status. Hurlburt thus argues that increasing the coordination between these two sectors may facilitate the targeting of scarce resources to children with the greatest levels of need. Bai et al. (2009), reporting on a study of child welfare-involved children over a 36-month period, concluded that the more intense the coordination between children's mental health and child welfare, the better the service access and child outcomes.

The question is, how do we achieve this level of childfocused service integration and coordination? An examination of service models locally and internationally points to three potential answers: integration through policy, integration through amalgamation and integration through collaboration.

The United Kingdom's approach arising from the Every Child Matters green paper (Boateng 2003) is perhaps the most frequently cited example of achieving service integration through policy. The future envisioned in this paper included a radical reorganization of all children's services to revolve around the needs of children and their families. Emphasis was placed on "joining up" children's services from prevention to early intervention, early years, special needs, child welfare, young offenders and elementary and secondary education. A Common Assessment Framework (CAF) was introduced to support interagency collaboration at the case level and to ensure that children receive the right combination of services at the appropriate time. Services are governed locally through children's trusts, which have the responsibility to commission services from provider agencies and hold them accountable for outcomes.

In Ontario, a more localized but promising dynamic that emerged a decade ago was the establishment of integrated child and family services agencies. These agencies are in place in a number of communities across the province and were formed by the amalgamation of multiple local children's service providers under a single governance structure. Services include child welfare, children's mental health and, in some cases, services such as youth justice, developmental services, early years and other family supports. Agencies have reported significant improvements in cross-sector collaboration, reduced service duplication and often a reduction in overall waiting lists for children's mental health services. Staff have reported an increased under- standing of roles and greater productivity in case conferencing and case management. Clients have expressed an appreciation of the "one number to call" and one door to access when they need help and support.

In Ontario, the most common current approach to integration lies in voluntary collaborative approaches between agencies. One example involves a pilot partnership between Kinark Child and Family Services (a children's mental health provider) and the CASs of Halton, Peel and Guelph/Wellington. These organizations have developed a service delivery model through which a youth, once identified to the service, becomes a shared responsibility. Priority of admission and types of service needs are agreed upon jointly by representatives from all partner agencies. The goal of the service is to stabilize the placement of children by developing behaviour management strategies that can be implemented by caregivers in the existing placement, thereby avoiding the need to move the child. A secondary goal is to increase the understanding and skills of foster parents and group home staff in addressing the mental health needs of youth in their care.

\section{... the more intense the coordination between children's mental health and child welfare, the better the service access and child outcomes.}

\section{Conclusion}

Kayley. Darius. Arjun. Carly. Robert. This article has provided a glimpse into their stories and the strategies that make a difference for them and thousands of others like them. But it has left a number of important issues unaddressed. The article has not attempted to speak to the profound and unique challenges relating to the child welfare and mental health needs of Aboriginal children and youth. Neither has it commented on the inherent issues in the level and distribution of funding for children's mental health services and the balance of funding to child welfare and other inter-related sectors. Finally, it has not examined the use of psychotropic drugs among children involved in child welfare - a matter that in recent years has been highlighted as an area of concern.

These unaddressed issues are a reminder of the many added complexities associated with meeting the mental health needs of children and youth who have experienced maltreatment. The four strategies described in this paper can - and are - making an important difference in the face of these complexities. These strategies hold tremendous potential to give our most vulnerable children and youth what we wish for all of our children - the opportunity to be happy and healthy, surrounded by the people and services that enable them to fully embrace life's opportunities. $\mathrm{HQ}$ 


\section{Acknowledgements}

This article has benefited significantly from the generous insights and case studies provided by multiple leaders in Ontario's child welfare and children's mental health sectors and in the Ministry of Children and Youth Services. The author also gratefully acknowledge the significant research support provided by Paul M. Jacobson, of Jacobson Consulting Inc.

The views presented in this article are those of the author only and do not represent the official position of any organization.

\section{References}

Bai, Y., R. Wells and M. Hillemeier. 2009. "Coordination between Child Welfare Agencies and Mental Health Providers, Children's Service Use and Outcomes." Child Abuse and Neglect 33(6): 372-81.

Boateng, P. 2003. Every Child Matters. Norwich, England: The Stationery Office. Retrieved February 7, 2010. <http://www.nscap. org.uk/doc/ECM.pdf>.

Burge, P. 2007. "Prevalence of Mental Disorders and Associated Service Variables among Ontario Children Who Are Permanent Wards." Canadian Journal of Psychiatry 52(5): 305-14.

Burns, B., S. Phillips, R. Wagner, R.P. Barth, D.J. Kolko, Y. Campbell et al. 2004. "Mental Health Need and Access to Mental Health Services by Youth Involved with Child Welfare: A National Survey." Journal of the American Academy of Child Adolescent Psychiatry 43: 960-70.

Crittenden, P. 2000. "A Dynamic Maturational Approach Exploration of the Meaning of Security and Adaptation: Empirical, Cultural and Theoretical Considerations." In P. Crittenden and A. Claussen, eds., The Organization of Attachment Relationships. Cambridge, United Kingdom: Cambridge University Press.

Czincz, J. and E. Romano. 2009. "Examining How the Mental Health Needs of Children Who Have Experienced Maltreatment Are Addressed within Ontario Children's Aid Societies." Canadian Journal of Family and Youth 2(1): 25-51.

Dixon, J. 2008. "Young People Leaving Care: Health, Well-Being and Outcomes." Child and Family Social Work 13: 207-17.

Dixon, J., J. Wade, S. Byford, H. Weatherly and J. Lee. 2006. Young People Leaving Care: A Study of Costs and Outcomes. London: Department of Education and Skills.

Draper, B., J. Pfaff, J. Pirkis, J. Snowdon, N. Lautenschlager, I. Wilson et al. 2008. "Long-Term Effects of Childhood Abuse on the Quality of Life and Health of Older People: Results from the Depression and Early Prevention of Suicide in General Practice Project." Journal of the American Geriatrics Society 56: 262-71.

Farmer, E.M.Z., B.J. Burns, M.V. Chapman, et al. 2001. "Use of Mental Health Services by Youth in Contact with Social Services." Social Services Review 75: 605-24.

Ford, T., P. Vostanis, H. Meltzer and R. Goodman. 2007. "Psychiatric Disorder among British Children Looked after by Local Authorities: Comparison with Children Living in Private Households." British Journal of Psychiatry 190: 319-25.

Fuller-Thomson, E. and S. Brennenstuhl. 2009. "Making a Link between Childhood Physical Abuse and Cancer." Cancer 115(14): 3341-50.

Gilbert, R. 2009. "Burden and Consequences of Child Maltreatment in High Income Countries.” Lancet 373(9657): 68-81.

Glisson, C. and P. Green. 2006. "The Role of Specialty Mental Health
Care in Predicting Child Welfare and Juvenile Justice Out-of-Home Placements." Research on Social Work Practice 16: 480-90.

Hurlburt, M.S., L.K. Leslie, J. Landsverk, R.P. Barth, B.J. Burns, R.D. Gibbons et al. 2004. "Contextual Predictors of Mental Health Service Use among Children Open to Child Welfare." Archives of General Psychiatry 61(12): 1217-24.

Kessler, R.C., G.P. Amminger, S. Aguilar-Gaxiola, J. Alonso, S. Lee and T.B. Ustun. 2007. "Age of Onset of Mental Disorders: A Review of Recent Literature." Current Opinion in Psychiatry 20: 359-64.

Krug, E.G., L.L. Dahlberg, J.A. Mercy, A.B. Zwi and R. Lozano. 2002. World Report on Violence and Health. Geneva, Switzerland: World Health Organization.

Laidlaw Foundation. 2010. Not So Easy to Navigate: A Report on the Complex Array of Income Security Programs and Educational Planning for Children in Care in Ontario. Toronto, ON: Author.

Leslie, L., M. Hurlburt, S. James, J. Landsverk, D.J. Slyman and J. Zhang. 2005. "Relationship between Entry into Child Welfare and Children's Mental Health Service Use." Psychiatric Services 56(8): 981-87.

Meltzer, H., R. Gatward, T. Corbin, R. Goodman and T. Ford. 2003. The Mental Health of Young People Looked after by Local Authorities in England. London: Her Majesty's Stationery Office.

O'Donnell, M., D. Scott and F. Stanley. 2008. "Child Abuse and Neglect: Is It Time for a Public Health Approach?” Australian and New Zealand Journal of Public Health 32(4): 325-30.

Ontario Association of Children's Aid Societies. 2006. Youth Leaving Care: An OACAS Survey of Youth and CAS Staff. Toronto, ON: Author.

Public Health Agency of Canada. 2010. Canadian Incidence Study of Reported Child Abuse and Neglect-2008: Major Findings. Ottawa, ON: Author.

Racusin, R., A.C. Maerlender, A. Sengupta, P.K. Isquirth and M.B. Straus. 2005. "Psychosocial Treatment of Children in Foster Care: A Review." Community Mental Health Journal 41(2): 199-221.

Raman, S., B. Inder and C. Forbes. 2005. Investing for Success: The Economics of Supporting Young People Leaving Care. Melbourne, Australia: Centre for Excellence in Child and Family Welfare.

Representative for Children and Youth of British Columbia. 2009. Kids, Crime and Care. Health and Well-Being of Children in Care: Youth Justice Experiences and Outcomes. Victoria, BC: Office of the Provincial Health Officer.

Ringeisen, H., C. Casaneuva, M. Urato and L.F. Stambaugh. 2009. "Mental Health Service Use During the Transition to Adulthood for Adolescents Reported to the Child Welfare System." Psychiatric Services 60(8): 1084-91.

Rowden, V. 2010, May 21. "Hazardous Passage for At-Risk Youth." The Star. Retrieved February 7, 2011. <http://www.thestar.com/ opinion/editorialopinion/article/812464--hazardous-passage-for-atrisk-youth>.

Sanders, L. and R.J. Fulton. 2009, June. The Bayfield Way: The Making of a Lexicon for Effective Residential Treatment for High Risk Adolescent Males. Paper presented at the ICPP Conference, Copenhagen, Denmark.

Select Committee on Mental Health and Addictions. 2010. Navigating the Journey to Wellness: The Comprehensive Mental Health and Addictions Action Plan for Ontarians. 2nd Session, 39th Parliament. 59 Elizabeth II. Toronto, ON: Author.

Stewart, S.L., A. Leschied, C. Newnham, L. Somerville, A. Armiere and J. St. Pierre. 2010. "Residential Treatment Outcomes with Maltreated 
Children Who Experience Serious Mental Health Disorders." OACAS Journal 55(1): 23-27.

Villigrana, M. 2010. "Mental Health Services for Children and Youth in the Child Welfare System: A Focus on Caregivers as Gatekeepers." Children and Youth Services Review 32: 691-97.

Waddell, C., D. Offord, C. Shepherd, J.M. Hua and K. McEwan. 2002. "Child Psychiatric Epidemiology and Canadian Public PolicyMaking: The State of the Science and the Art of the Possible." Canadian Journal of Psychiatry 47(9): 825-32.

Winokur, M., A. Holtan and D. Valentine. 2009. "Kinship Care for the Safety, Permanency and Wellbeing of Children Removed from Their Homes for Maltreatment." Cochrane Database of Systematic Reviews 1: CD006546.

\section{About the Author}

Ene Underwood, MBA, is the chair of the Commission to Promote Child Welfare, based in Toronto, Ontario. Established in 2009 by the Ontario government, the commission has a three-year mandate to develop and implement recommendations to improve the sustainability and outcomes of child welfare. Prior to accepting this role, Ms. Underwood held multiple executive positions in healthcare relating both to system restructuring and operational management. She can be contacted by e-mail at ene. underwood@ontario.ca.

\section{You like us here,}

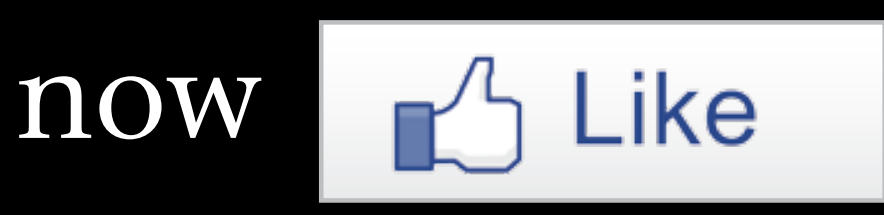

\section{us there.}

